\title{
LOS MEDIOS PROBATORIOS EN COLOMBIA Y SU INCIDENCIA EN EL ENCARGO DE UNA AUDITORİA: UNA PERSPECTIVA DESDE EL PENTÁGONO DEL FRAUDE *
}

\author{
Means of proof in Colombia and its occurrence within an audit \\ engagement: A perspective of the Pentagon of fraud
}

Ludivia Hernández Aros**

Rodrigo Alberto Plazas Estepa***

Mario-Heimer Flórez-Guzmán***

Recepción: 23 de abril de 2018. Aceptado: 10 de julio de 2018.

DOI: http://dx.doi.org/10.21017/Rev.Repub.2018.v25.a52

\section{RESUMEN}

El presente artículo de investigación da cuenta de la incidencia que tiene la debida aplicación de los medios probatorios en Colombia en la efectividad del encargo de auditoría, a partir de la identificación de las variables que se ponen de manifiesto en el pentágono del fraude. Se parte de la problemática actual en procesos judiciales en los cuales el contador actúa en calidad de perito, y entonces se evidencia que algunas de las pruebas presentadas ante un juez, y que pretenden servir -en ese proceso- como material probatorio, no son tenidas en cuenta por no obedecer a los principios de ser amplias, suficientes y competentes,

* Artículo derivado de proyecto de investigación «Diseño de estrategias que incidan en los mecanismos de recolección de pruebas en una auditoría forense que propendan por mitigar el riesgo en las organizaciones»; proyecto en el cual se investigó todos los roles del contador público para asegurar la información financiera de las organizaciones.

* Magíster en Auditoría y Gestión Empresarial de la Universidad UNINI, Puerto Rico. Especialista en Revisoría Fiscal y Control de Gestión de la Universidad Cooperativa de Colombia. Profesora investigadora de la Facultad de Contaduría Pública de la Universidad Cooperativa de Colombia, sede Ibagué, integrante del grupo de investigación Planaudi. Correo electrónico: Ludivia.hernandez@campusucc.edu.co

** Estudiante de Doctorado en Derecho de la Universidad de Buenos Aires (República Argentina). Magíster en derecho y abogado de la Universidad Sergio Arboleda. Investigador asociado de Colciencias. Correo electrónico: rodrigoplazas@urepublicana.edu.co

* Doctorando en Ciencias de la Educación. Licenciado en Matemáticas y Física. Auditor Integral en Sistemas de Gestión. Director del Institucional del Centro de Investigaciones de Colombia CIIN-Colombia; profesor investigador asociado de Colciencias, Correo electrónico: mariohfg@hotmail.com 
careciendo, por lo tanto, de toda validez. Desde el aspecto metodológico, es una investigación de tipo documental, que utiliza técnicas de análisis crítico de la información que permitieron compilar la información para hacer un análisis del problema objeto de estudio. Como reflexión final se obtuvo que el pentágono del fraude, como herramienta que caracteriza los diferentes eventos de fraude que se pueden presentar en una organización, ha sido ampliamente identificado y brinda elementos importantes en el encargo de auditoría, que una vez articulado de estricta manera con la aplicación de los elementos propios de los medios probatorios en Colombia, permite aumentar la eficacia y minimizar los riesgos en el levantamiento de la información como material probatorio en un proceso judicial.

Palabras clave: pentágono del fraude, proceso judicial, medios probatorios en Colombia.

\section{ABSTRACT}

This research paper aims to reveal the incidence of a proper application of the rules of evidence in Colombia, concerning the effectiveness of an audit engagement. This stems from the identification of variables settled in the Pentagon of fraud. The starting point relies on the conundrum of giving expert evidence as an accountant within a trial. It becomes stark that some evidence was not taking into account because it does not dovetail with the principles of being broad, sufficient and competent. Therefore, the evidence was lacking any reasonable validity and reliability. In terms of the methodology, this is a documentary-approach research, using techniques of critical analysis of data. Such an approach allowed collecting data so as to analyze the problem of study. As a conclusion, using the Pentagon of fraud as a tool to characterize different events of a fraud that may arise in companies has been widely identified and brings relevant elements in an audit engagement. The strict articulation with the proper application of the rules of evidence in Colombia allows increasing the efficiency and decreasing the risks insofar as the collection of data as evidence material within a judicial process.

Keywords: pentagon of fraud, judicial process, evidence in Colombia.

\section{INTRODUCCIÓN}

Actualmente las organizaciones se enfrentan frecuentemente a situaciones de fraude, las cuales -en algunos momentos- no logran ser percibidas por los auditores o por los encargados de la salvaguarda de sus activos (Flórez-Guzmán, 
Hernández Aros \& Gallego Cossio, 2015); con base en lo anterior, en las organizaciones, en las firmas de auditoría y de parte de los profesionales que asumen un encargo de auditoría, es normalmente escuchado el término «pentágono del fraude», el cual ha evolucionado a tal punto que ahora se conoce como «la geometría del fraude». Se debe resaltar que el fenómeno del fraude ha tenido varias etapas, la primera de ellas, cuando se contemplaban las variables de presión, oportunidad y racionalización, como aquellas que permitían de forma significativa el cometimiento de un delito; posteriormente, se contempló la variable de conocimiento o capacidad, etapa conocida como el diamante del fraude; y actualmente se adiciona otra variable más, denominada «motivación», para llegar al término del pentágono del fraude; término que ha servido como herramienta fundamental para poder generar indicios de fraude en el interior de las organizaciones (Galvis-Castañeda, I. E., \& Santos-Mera, J. E., 2017).

Así las cosas, Aros \& Cossio (2015) plantean que, en la misma medida en la que evoluciona el fraude, deben evolucionar los sistemas de control en las organizaciones, las cuales, desde el control interno y actuando en pro de la salvaguarda de sus activos, deben procurar la generación de confianza en todos los grupos de interés Stakeholders, emitir información -financiera y no financierareal, verificable y confiable que permita la toma asertiva de decisiones que propendan por la continuidad del ente económico.

Ahora bien, es deber del Estado velar y proporcionar los mecanismos necesarios para que las organizaciones, los encargados del control y todos aquellos que tienen bajo su custodia los activos de la organización y la salvaguarda de la confianza pública cuenten con herramientas que permitan valorar los riesgos a los que se exponen las organizaciones y poder mitigarlos tanto en el campo organizacional, como en el de los profesionales que ejercen el encargo de auditoría, toda vez que, aunque las herramientas de auditoría reglamentadas a nivel nacional e internacional proveen algunas herramientas, se hace necesario que los profesionales que aceptan el encargo tengan en cuenta los procedimientos legales que permitan revestir de legalidad, veracidad y pertinencia las pruebas que se recojan en el proceso de auditoría, a fin de que puedan ser tenidas en cuenta en un proceso judicial, mejorando de esta manera, la efectividad del levantamiento de la prueba y el dictamen pericial en el encargo (Curvelo Hassán, y otros, 2018).

Por lo anterior, el presente artículo abordará los conceptos básicos de los aspectos legales de la prueba, los medios probatorios en el encargo de auditoría y la tipificación de las variables del pentágono del fraude de cara a la efectividad en el levantamiento de la prueba en un encargo. 


\section{PROBLEMA DE INVESTIGACIÓN}

El más reciente estudio publicado por la firma de auditoría $\mathrm{KPMG}^{1}$-abril de 2018-, el cual establece por medio de una encuesta a altos funcionarios, la caracterización del fraude en Colombia, expone que los principales problemas que hacen que se presente este tipo de situaciones radican en la falta de efectividad en los controles internos, además de la debilidad en la cultura ética por parte de los empleados de las organizaciones (KPMG, 2018). Por otra parte, el estudio muestra que en el $85 \%$ de los casos fue posible identificar al perpetrador o perpetradores; sin embargo, en un $11 \%$ no fue posible, y concluye argumentando que aún en las compañías existe una gran brecha en el proceso de investigación a pesar de los avances significativos que han tenido estas en materia de lucha contra el crimen económico.

Asimismo, en las organizaciones las concentraciones mayores de delitos financieros están en malversación de activos (robo de dinero) con un 35\%, malversación de activos (robo o daño de inventario) 16\%, corrupción (soborno) $15 \%$, corrupción (conflicto de intereses) $11 \%$, fraude financiero (manipulación de flujo de caja) 5\%, fraude financiero (manipulación de indicadores financieros) $4 \%$, entre otros, que se constituyen en elementos de fraude que se encuentran ampliamente tipificados en el pentágono del fraude y que en su mayoría están dentro de las variables oportunidad, motivación y presión, que son las que principalmente influyen en el cometimiento de actos delictivos por parte del perpetrador, sin dejar a un lado -aunque en situaciones de menor frecuencia relativa- las variables de capacidad y racionalización (KPMG, 2018).

Ahora bien, según la información emitida por KPMG hacia la respuesta a la pregunta ¿qué acción tomó una vez que probaba la evidencia del evento de fraude?, el 38\% de los encuestados manifestó que inició una acción judicial en contra del implicado y, en segundo lugar -en un $28 \%$-, realizan una denuncia ante los organismos pertinentes, lo que hace importante que quien ejerce el proceso de auditoría tenga pleno conocimiento legal para el levantamiento de pruebas a fin de que estas puedan ser tenidas en cuenta por parte del juez. Así las cosas, en una pregunta de la encuesta, como fue ¿se pudo recuperar las pérdidas al evento de fraude?, el $45 \%$ de los encuestados plantean que no y el $42 \%$ manifiestan que se hizo parcialmente; por consiguiente, podría

1 KPMG es una red global de firmas que prestan los servicios de auditoría, impuestos y consultoría. En Colombia es una de las más reconocidas firmas de auditoría y asesoría del país, con un importante portafolio de clientes nacionales y multinacionales (KPMG, 2018). 
suponerse que en ese $45 \%$ no se establecieron las formas precisas que coaccionaran al perpetrador a responder por el acto delictivo que cometió (KPMG, 2018).

A lo anterior, hay que adicionarle que los contadores, y en general las personas que tienen a su cargo los procesos de auditoría, no tienen pleno conocimiento de las normas que en el estado colombiano regulan la presentación de la evidencia amplia, suficiente y relevante en un proceso judicial; situación por la cual, el Derecho de la Presunción de Inocencia a quien le es imputada la sospecha de fraude, prima sobre toda sospecha hasta que no se presente la prueba que determine la culpabilidad del sujeto.

En este aspecto jurídico, a todo acusado hay que proporcionar la seguridad de que no será acusado sin que existan las pruebas suficientes que desestimen la presunción de inocencia y que, a su vez, demuestren su culpabilidad mediante la expedición de una condena sancionatoria en su contra; es así, como existe una gran importancia en la prueba de cargo, aquella que se allega a la instancia judicial con el objetivo de que esta debe estar libre de duda razonable, lo que en caso contrario, obligaría a absolverse por carecer de dicho criterio; asimismo, se estima que la verdad iuris tantum solo puede desvirtuarse por una prueba de cargo aportada por la parte acusadora (Contribuciones a las Ciencias Sociales, 2012).

Frente al panorama anterior, este estudio consideró las siguientes preguntas generadoras: ¿Cuál es el aporte de los medios probatorios para que el auditor identifique las variables del pentágono del fraude?, ¿Por qué es importante el establecer las variables del pentágono del fraude en un encargo de auditoría forense? ¿Hasta dónde el material probatorio dentro de un proceso jurídico presentado por el auditor forense es desestimado por carecer de los principios de ser una prueba amplia, suficiente y competente?

\section{ESTRATEGIA METODOLÓGICA}

La presente investigación es de corte documental, de carácter descriptivo-explicativo, con un enfoque propositivo, social, interdisciplinario. Desde la estructura del documento, se hace énfasis en los aspectos legales de la prueba, los medios probatorios en el encargo de auditoría y la tipificación de las variables del pentágono del fraude de cara a la efectividad en el levantamiento de la prueba en un encargo de auditoría, con el marco de referencia de las Normas Internacionales de Aseguramiento de la Información, NAI. 


\section{RESULTADOS}

\section{La prueba y sus aspectos legales}

La validez de la prueba es una propiedad que generalmente se atribuye a los aportes documentales, testimoniales u otros elementos de juicio que serán apreciados y valorados en un juzgado para dirimir sobre hechos controversiales; pero para saber cuándo esa cualidad se encuentra presente, es necesario hacer referencia a la legalidad y a la licitud de la misma, aspectos que actúan como filtros en defensa del bloque de constitucionalidad (Corte Constitucional, Sentencia C-067/03).

Esto es, que mientras que la inobservancia de la primera afecta el debido proceso, por vulnerar las formas propias del juicio (desde el punto de vista formal), la ilicitud se predica cuando, en el mismo sentido, se transgreden las formas propias del juicio (pero desde una perspectiva sustancial); dicho de otro modo, cuando en su obtención se cuestionan los derechos fundamentales (Corte Constitucional, Sentencia T-916/08).

En materia probatoria, las formalidades implican el respeto por la legalidad, y se aplican a todo tipo de actuaciones, las cuales van desde la solicitud, la admisión, la incorporación y la valoración de los elementos de juicio; mientras que desde lo sustancial, implica el respeto de las garantías procesales, las cuales engloban tres aspectos fundamentales: (1) la presunción de inocencia, mientras exista una decisión en firme que declare lo contrario; (2) el derecho a ejercer la defensa (material y técnica a través de un abogado); y (3) el derecho a conocer, presentar y a controvertir las pruebas que se alleguen en su contra, así como a impugnar las decisiones, siendo en todo caso nula la prueba obtenida con violación de los anteriores preceptos (Constitución Política de Colombia, Artículo 29).

En este sentido, al respeto de los anteriores supuestos de derecho, se garantiza que la prueba obtenida sea válida, creíble, y susceptible de ser apreciada o estimada. Ahora bien, para saber cuáles son los elementos de juicio, el Código General del Proceso describe la existencia de diferentes medios de convicción, tales como «la declaración de parte, el juramento, el testimonio de terceros, el dictamen pericial, la inspección judicial, los documentos, los indicios y cualesquiera otros medios que sean útiles para la formación del convencimiento» (Ley 1564 de 2012, artículo 175).

En este contexto, cada medio de convicción contiene una ritualidad propia, la cual se encuentra consagrada en el ordenamiento procesal, que por ser de orden público, es de obligatorio cumplimiento; en caso contrario, el riesgo 
de invalidar el acto es inminente, o en su defecto, que la actuación sea inexistente, razón por la cual, es importante señalar que las estipulaciones de las partes que controviertan lo dispuesto por el ordenamiento se tendrán por no escritas (Ley 1564 de 2012, artículo 13).

No se puede pasar por alto que la validez es un tema que no puede ser objeto de estudio solo desde el plano legal y/o sustancial, porque la solicitud, la admisión, la incorporación y la valoración de la prueba generan diferentes problemas desde la filosofía jurídica, en razón a que las decisiones tienen la potencialidad de afectar a la persona de manera individual, y a la sociedad en general (Ruiz, 2009).

Concomitante con lo anterior, se advierte que en el proceso de interpretación de la ley procesal se deberá tener en cuenta la efectividad de los derechos reconocidos por la ley sustancial; y ante la duda, deberán siempre aplicarse los principios y los derechos constitucionales fundamentales, absteniéndose siempre el juez de exigir formalidades innecesarias (Ley 1564 de 2012, artículo 11).

\section{Los medios probatorios en un encargo de auditoría}

Cuando se trate de la actuación del auditor, como parte, como perito o como tercero, en este último caso, servirá de auxiliar de justicia, y en este sentido, el Código de procedimiento civil expresa en su artículo 8 que los cargos de auxiliares de justicia «(...) son oficios públicos que deben ser desempeñados por personas idóneas, de conducta intachable, excelente reputación e incuestionable imparcialidad. (...) se exigirán versación y experiencia en la respectiva materia y, cuando fuere el caso, título profesional legalmente expedido» (Código de Procedimiento Civil, artículo 8).

El auditor, al aceptar un encargo de auditoría, debe preparar sus papeles de trabajo, que se convierten en pruebas dentro de un proceso, y para ello, cada una de ellas debe atender los lineamientos que la ley otorga. En este sentido, y dependiendo del tipo de proceso que se genere, el auditor tendrá en cuenta el Código de Procedimiento Civil (Decreto 1400 de 1970), el Código Penal (Ley 906 de 2004), el Código General del Proceso (Ley 1562 de 2012), la Constitución Política de Colombia de 1991, y demás normas propias de su experticia como el Decreto 2420 de 2015 en su anexo 4, el Decreto 2170 de 2017, entre otros.

Dentro de los medios probatorios el Código General del Proceso en su artículo 165 expresa que los mismos:

Sirven como pruebas, la declaración de parte, la confesión, el juramento, el testimonio de terceros, el dictamen pericial, la inspección judicial, los 
documentos, los indicios, los informes y cualesquiera otros medios que sean útiles para la formación del convencimiento del juez (Colombia, Congreso de la República, Ley 1564 de 2012, art. 165).

Atendiendo que es un encargo de auditoría, este debe ser un proceso sistemático planificado, que busca evaluar controles, revelar errores, descubrir fraudes, entre otros aspectos, y para ello, el auditor cumplirá con el proceso que lo rige como es: a) la planeación, b) ejecución, c) informe y d) monitoreo.

Para la planeación, se parte de un contrato de aseguramiento de la información, que está previsto en la NIA 100, y que consiste en el documento legal en donde se dejan plasmadas las responsabilidades de la gerencia con respecto a la información a entregar, la responsabilidad del auditor y su alcance, el tiempo de ejecución, los honorarios, entre otros aspectos (Decreto Reglamentario 2420 de 2015. Anexo 4. NIA 100).

Una vez el encargo de auditoría esté formalizado, el auditor, atendiendo a la NIA 300, preparará un memorando de planeación -documento que consiste en plasmar, de una forma muy precisa, los programas de auditoría con las actividades a realizar y las fechas, personal a ejecutar, papeles de trabajo a obtener-, y para ello, parte de un análisis previo de la organización a auditar, la materialidad o la importancia relativa ${ }^{2}$ de las cifras financieras, el entorno económico en que se desenvuelve la empresa y los riesgos detectados a través de la Matriz DOFA.

Frente a la ejecución, es el proceso donde se toma la evidencia que sirve de prueba dentro del proceso, y en este aspecto, el auditor deberá obtenerla con toda la validez jurídica, para que no sea desestimada. Orta, Castillo, SánchezMejía \& Sierra (2012) afirman que la evidencia de auditoría es un elemento fundamental a la hora de plantear las pruebas. La ejecución representa la obtención de todo tipo de evidencia: documental, física, digital, testimonial, entre otras, que soporta la validez de un informe final.

2 La NIA 320, frente a este aspecto, argumenta que la importancia relativa o materialidad para la ejecución del trabajo se refiere a la cifra o cifras determinadas por el auditor, por debajo del nivel de la importancia relativa establecida para los estados financieros en su conjunto, al objeto de reducir a un nivel adecuadamente bajo la probabilidad de que la suma de las incorrecciones no corregidas y no detectadas supere la importancia relativa determinada para los estados financieros en su conjunto. En su caso, la importancia relativa para la ejecución del trabajo también se refiere a la cifra o cifras determinadas por el auditor por debajo del nivelo niveles de importancia relativa establecidos para determinados tipos de transacciones, saldos contables o información a revelar (Decreto 2420 de 2015, NIA 320, p. 1748). 
En términos del informe, expresa el alcance, las actividades realizadas, los hallazgos y la opinión -no modificada (favorable) u opinión modificada-frente a los hechos investigados. En este aspecto, el Decreto 2170 de 2017 contiene las normas internacionales aplicadas en Colombia, frente a lo referido por la NIA 700, 701, 705 y 706.

Dentro del informe final, se debe dejar claro si el compromiso de aseguramiento fue a) razonable, cuando se obtiene evidencia suficiente y apropiada con valoración de riesgos, aplicación de procedimientos adicionales de inspección, confirmación, recálculo, redesempeño, procedimientos sustantivos y procedimientos de control; y b) aseguramiento limitado: este se da cuando se obtiene evidencia suficiente y apropiada, pero los procedimientos son limitados de manera deliberada.

El monitoreo representa una necesidad fundamental para la auditoría, que permite que se puedan modificar los procedimientos y pruebas de auditoría de ser necesario- para ofrecer un resultado de mayor valor y calidad. El monitoreo permite a la gerencia determinar los asuntos en los que debiera enfocarse, y es así que la gerencia puede mejorar procesos, implementar cursos de acción correctiva, gestionar riesgos y asegurarse de mejor manera que la institución pueda lograr sus objetivos (Fernández, 2016).

\section{El pentágono del fraude y los medios de prueba}

El pentágono del fraude se presenta dentro de las organizaciones a partir de cinco (5) variables: a) la motivación, b) la presión, c) la racionalización, d) la capacidad y e) la oportunidad, que afectan gravemente a las finanzas y, por supuesto, el ambiente de control (Ver tabla 1).

En este contexto, se presenta una matriz de riesgos que analiza las variables del fraude y relaciona las evidencias que el auditor forense debe tener en cuenta en el encargo para el cual fue contratado (Ver figura 1).

En este orden de ideas, para analizar cada una de estas variables de fraude y su respectivo medio probatorio, se inicia con la revisión y análisis de la normatividad así:

A. La declaración de parte: El Código General del Proceso (CGP) contempla en su artículo 191 y siguientes la declaración de parte como medio de prueba, que consiste «en una declaración de conocimiento del individuo sobre la existencia o inexistencia de hechos materia de discusión, y que se realiza audiencia ante el juez, ya sea a petición de alguna de las partes o por orden de la autoridad judicial.» (Colombia. Congreso 
Tabla 1. Tipificación de las variables del pentágono del fraude

Variable del fraude

La motivación

Razón principal

\section{Representa}

Es el hecho de que el sujeto percibe su realidad y en función de ella orienta su conducta con la expectativa de lograr un objetivo específico. La motivación es la fuerza que impulsa la acción, es lo que hace que el sujeto pase de pensar a hacer.

Lapresión

Influencia externa o interna

Constituye las condiciones de exigencia externa con características de refuerzo negativo. El perpetuador es presionado por un tercero, por su familia, por la misma organización; en fin, son muchas las circunstancias que le pueden generar presión.

\section{La racionalización}

Justificación basada en creencias o afirmaciones

El defraudador mantiene un diálogo interno, un conjunto de ideas que autoverbaliza in sensu, con las que busca mantener su imagen de no culpable o no responsable de la situación fraudulenta.

\section{La capacidad \\ Uso del conocimiento, habilidades y destrezas}

Implica el uso de la experiencia, la habilidad y la competencia del sujeto para cometer el fraude, en especial cuando hace referencia al fraude ocupacional.

La oportunidad

Momento adecuado, producto de las debilidades de control.

Son circunstancias medioambientales, que facilitan la acción y posterior protección del individuo, para reducir el riesgo de ser sorprendido o responsabilizado por el fraude.

Fuente: Galvis-Castañeda \& Santos-Mera (2017), adaptado y modificado por los autores. 


\begin{tabular}{|c|c|c|c|c|c|c|}
\hline NIVEL 1 & Nunca ocurrirá & & & & & \\
\hline NIVEL 2 & posiblemente ocurra & & & & & \\
\hline NIVEL 3 & Siempre sucederá & & & & & \\
\hline \multicolumn{7}{|c|}{ Matriz de Riesgos } \\
\hline $\begin{array}{l}\text { Variable del } \\
\text { Fraude }\end{array}$ & Brere descripciön & Amenaza & Riesgo & Eridencia & Acciones de Mejora & Nirel \\
\hline \multirow{2}{*}{ Motivación } & \multirow[t]{2}{*}{$\begin{array}{l}\text { Fuera que impulsa al sujeto para que } \\
\text { ejecute el fraude "Un motno" }\end{array}$} & \begin{tabular}{|l|}
$\begin{array}{l}\text { Ser aceptado por un gnupo: anigos } \\
\text { fammilares, un ser quenido }\end{array}$ \\
\end{tabular} & Riesgo inherente & \multirow{2}{*}{$\begin{array}{l}\text { Llamadas y o risitas de } \\
\text { cobro, cambio de } \\
\text { aspecto personaly } \\
\text { socioeconomico }\end{array}$} & $\begin{array}{l}\text { Campanass motivacionales donde se le otorge la } \\
\text { oportunidad al trabajador de ser escuchado. }\end{array}$ & \multirow{2}{*}{3} \\
\hline & & $\begin{array}{l}\text { Necesidades económicas del } \\
\text { defraudor }\end{array}$ & Riesgo de Control & & Analisis al ingreso del personal y segumiento. & \\
\hline \multirow[b]{2}{*}{ Presion } & \multirow{2}{*}{$\begin{array}{l}\text { Situaciones de orden social y economico } \\
\text { que haacen presión en el sujeto }\end{array}$} & $\begin{array}{l}\text { Persona ulunerable con falta de } \\
\text { caracter y criterio }\end{array}$ & Riesgo inherente & \multirow[b]{2}{*}{$\begin{array}{l}\text { Correos Electronicos, } \\
\text { Llamadas, Testigos }\end{array}$} & $\begin{array}{l}\text { Onienteción constantes sobre finanzas personales, } \\
\text { fondos y cooperativas que facititan dineroa tasas } \\
\text { infeniores a las del mercado. }\end{array}$ & \multirow[b]{2}{*}{2} \\
\hline & & $\begin{array}{l}\text { Presion economica, enfemedades } \\
\text { del grupo familiar, necesidad de ser } \\
\text { aceptado por un grupo o un ser } \\
\text { quenido }\end{array}$ & Riesgo de Control & & $\begin{array}{l}\text { Gestionar para los empleados onientaciones sociales, } \\
\text { psicologicas, tida familiar, manejo de estres, uso de } \\
\text { tiempo bbre, economia personal, emprendimiento } \\
\text { fammiar, entre otros }\end{array}$ & \\
\hline Racionalización & $\begin{array}{c}\text { El sujeto se autojustifica, tiene clanidad de } \\
\text { que la accion que va acometer es } \\
\text { fraudulenta y atenta contra valores morales, } \\
\text { sociales e incluso reglas legales. }\end{array}$ & $\begin{array}{l}\text { Hablidad en la foma de hablary } \\
\text { proceder. } \\
\text { Se disfraza lo que sucede }\end{array}$ & Riesgo de control & $\begin{array}{c}\text { Manual de Procesos y } \\
\text { Procedinientos-Control } \\
\text { Intemo }\end{array}$ & $\begin{array}{l}\text { Campañas de comuricaciön con mensajes cortos, de } \\
\text { fácil comprensiön, que trabajen aspectos de pertenecia } \\
\text { a la organizaciön, sentido humano, etica empresanal }\end{array}$ & 2 \\
\hline \multirow[t]{2}{*}{ Capacidad } & \multirow{2}{*}{$\begin{array}{l}\text { El sujeto conoce todos los aspectos de la } \\
\text { organización, ha sido formado en detalle } \\
\text { sobre aspectos puntuales y posee todas las } \\
\text { herramientas para realizar el fraude. }\end{array}$} & Exceso de Conocimiento & \multirow[t]{2}{*}{ Riesgo de Control } & \multirow{2}{*}{$\begin{array}{c}\text { Conocimiento suficiente } \\
\text { del Softrare. Resistencia } \\
\text { a rotacion del cargo }\end{array}$} & $\begin{array}{l}\text { Analizar las habilidades, competencias y conocimientos } \\
\text { que pueden o no relacionarse con el perfil de cargo } \\
\text { desempenado por una persona. }\end{array}$ & \multirow[t]{2}{*}{3} \\
\hline & & Falta de controles & & & $\begin{array}{l}\text { Conocer y entender los peffiles de capacidad de su } \\
\text { personal }\end{array}$ & \\
\hline \multirow{3}{*}{ Oportunidad } & \multirow{3}{*}{$\begin{array}{l}\text { El fraude se realiza ya que existen vacios de } \\
\text { control y son aquellas espacios que el } \\
\text { sujeto aprovecha para cometer el hecho } \\
\text { fraudulento }\end{array}$} & $\begin{array}{l}\text { Ausencia de seguimiento al control } \\
\text { intemo. }\end{array}$ & \multirow{3}{*}{$\begin{array}{l}\text { Riesgo de Control, } \\
\text { Riesgo de Detecciön }\end{array}$} & \multirow{3}{*}{$\begin{array}{c}\text { Manual de Procesos y } \\
\text { Procedinientos-Control } \\
\text { Intemo, } \\
\text { Fallas en el Sottware }\end{array}$} & $\begin{array}{l}\text { Se analizan los métodos y herramientas de control, se } \\
\text { establecen nuevos protocolos. }\end{array}$ & \multirow{3}{*}{; } \\
\hline & & Exceso de confianza & & & $\begin{array}{l}\text { Se establecen nuevas nomas con la expectativa de } \\
\text { reducir las fallas, los daños y las perdidas. }\end{array}$ & \\
\hline & & Fallas en el sottuare & & & $\begin{array}{l}\text { Se aumenta el uso de tecnologia para fortalecer } \\
\text { capacidad de monitoreo. }\end{array}$ & \\
\hline
\end{tabular}

Figura 1. Matriz de riesgos a partir de la tipificación de las variables del pentágono del fraude.

Fuente: Los autores.

de la República, Ley 1564 de 2012, art. 191). En este proceso, las pruebas constituyen la base para formular las preguntas del interrogatorio, de tal manera que se integren todas las etapas del fraude en el desarrollo de la investigación.

B. La confesión: Esta se genera mediante una declaración que realiza la persona investigada, en la cual acepta los cargos que se le imputan. Con respecto a la misma el CGP, en su artículo 191, expresa que 1) El confesante tenga capacidad para hacerla y poder dispositivo sobre el derecho que resulte de lo confesado. 2) Verse sobre hechos que produzcan consecuencias jurídicas adversas al confesante o que favorezcan a la parte contraria. 3) Recaiga sobre hechos respecto de los cuales la ley no exija otro medio de prueba. 4) Sea expresa, consciente y libre. 5) Verse sobre hechos personales del confesante o de los que tenga o 
deba tener conocimiento, y 6) Que se encuentre debidamente probada, si fuere extrajudicial o judicial trasladada (Colombia, Congreso de la República, Ley 1564 de 2012, art. 191).

C- El juramento: Frente a este aspecto, el Código Penal estima que toda autoridad a quien corresponda tomar juramento amonestará previamente a quien debe prestarlo acerca de la importancia moral y legal del acto y las sanciones penales establecidas contra los que declaren falsamente o incumplan lo prometido, para lo cual se leerán las respectivas disposiciones y acto seguido se tomará el juramento por medio del cual el testigo se compromete a decir toda la verdad de lo que conoce (Ley 906 de 2004). En este aspecto se prevé que, en el momento previo a una declaración o un testimonio, se genera el juramento. De igual forma, el artículo 82 del CGP contempla el juramento estimatorio, como una estimación razonada, en la demanda o petición, de quien pretenda el reconocimiento de una indemnización, compensación o el pago de frutos o mejoras, discriminando cada uno de sus conceptos (Colombia, Congreso de la República, Ley 1564 de 2012, art. 82).

D. El testimonio: A nivel procesal, el testimonio se trata de la declaración bajo juramento de un individuo que tiene conocimiento de los hechos controversiales y puede aportar evidencias a la investigación. Para que sea válido, se debe solicitar dentro del acápite de las pruebas de la demanda, y anexar la explicación sobre el fin que se persigue; después el juez debe ordenarlo.

E. El dictamen pericial: Este se presenta como un informe, que «(...) exige cierto grado de investigación sobre los hechos económicos controversiales, donde reposa una opinión, y contiene los elementos necesarios para influir en la decisión del Juez y poder fallar de acuerdo a las evidencias presentadas» (Caro, Hernández, Gallego \& Flórez, 2015, p. 101).

F. La inspección judicial: Es definida como la práctica de examinar, verificar, investigar «(...) sobre personas, lugares, cosas o documentos que hayan de ser materia de un proceso, con o sin intervención de perito» (Código del procedimiento Civil, art. 300).

G. Los documentos: Representa los soportes físicos que se presenten dentro del proceso y que requieren del cumplimiento de los aspectos legales que en ellos se exige. En este aspecto, el CGP, en su artículo 243, contempla que son documentos los escritos, impresos, planos, dibujos, cuadros, mensajes de datos, fotografías, cintas cinematográficas, dis- 
cos, grabaciones magnetofónicas, videograbaciones, radiografías, talones, contraseñas, cupones, etiquetas, sellos y, en general, todo objeto mueble que tenga carácter representativo o declarativo, y las inscripciones en lápidas, monumentos, edificios o similares (Colombia, Congreso de la República, Ley 1564 de 2012, art. 243). Los mismos deben ser auténticos, de alcance probatorio, sin tachones o enmendaduras, y no deben estar rotos o alterados.

H. Los indicios: Son una prueba crítica, lógica, indirecta. El indicio es un hecho del cual se infiere otro desconocido. Debe quedar suficientemente claro que el indicio es, por así decirlo, un hecho especialmente cualificado, porque tiene la propiedad de salirse de sí mismo y mostrar otro (Quijano, s. f.). Los artículos 241 y 242, del CGP, exponen que el juez podrá deducir indicios de la conducta procesal de las partes. El juez apreciará los indicios en conjunto, teniendo en consideración su gravedad, concordancia y convergencia, y su relación con las demás pruebas que obren en el proceso (Colombia, Congreso de la República, Ley 1564 de 2012, art. 241 y 242).

I. Los informes: Estos son escritos que «a petición de parte o de oficio el juez podrá solicitar informes a entidades públicas o privadas, o a sus representantes, o a cualquier persona sobre hechos, actuaciones, cifras o demás datos que resulten de los archivos o registros de quien rinde el informe, salvo los casos de reserva legal. Tales informes se entenderán rendidos bajo la gravedad del juramento por el representante, funcionario o persona responsable del mismo» (Colombia, Congreso de la República, Ley 1564 de 2012, art. 275).

J. Otros medios: Dentro de esta investigación se pueden anexar al proceso algunos documentos como: noticia criminal, oficio suscrito por implicados, oficios suscritos por terceros, informe de investigador de campo, formato de ingreso de evidencia, carta rogatoria, orden de policía judicial, entre otros.

En este orden de ideas, ¿cómo estos medios probatorios apoyan al auditor forense en su labor para detectar las variables del fraude? (Ver figura 2).

Frente a este panorama, cada uno de los medios probatorios, pueden ser usados por el auditor forense para identificar las variables del pentágono del fraude.

Partiendo de las etapas de la auditoría forense -planeación, ejecución, informe y monitoreo-, analizadas con anterioridad, el auditor puede apoyarse en los 
medios probatorios para detectar el pentágono del fraude así: puede solicitar en la empresa una declaración de parte de los hechos controversiales, inicialmente al contador público (dador de fe pública), al administrador como engranaje de cada uno de los procesos internos de la organización, y demás personas que pudiesen estar implicados. Se parte del principio de que el contador conoce la minucia de todos los procesos contables y que el administrador, además, es el responsable de la información financiera; la ley, en este caso el Código de Comercio, en su artículo 200, establece que ambos deberán responder solidaria e ilimitadamente por los perjuicios que por dolo o culpa ocasionen a la sociedad, a los socios o a terceros.

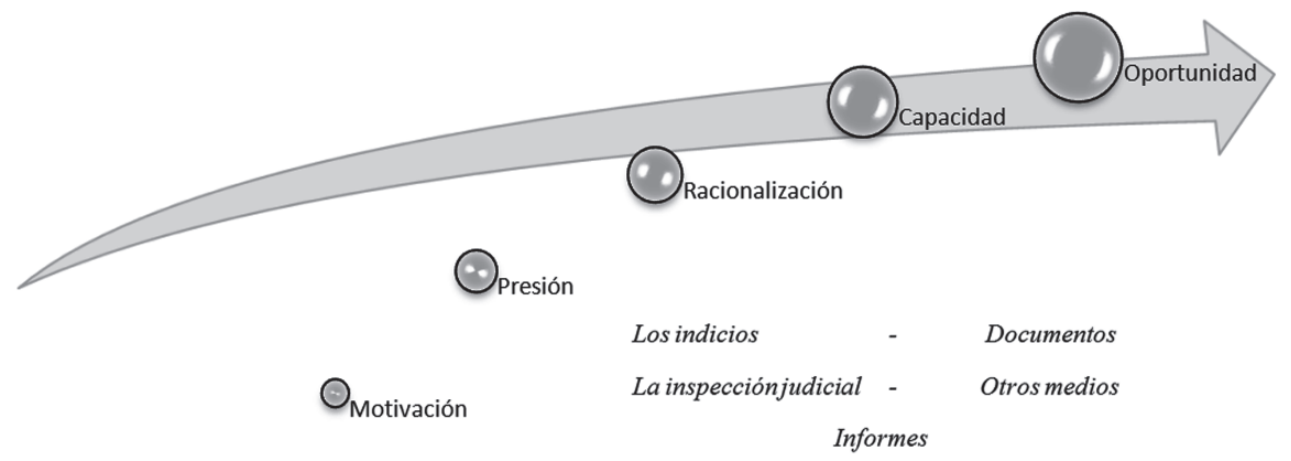

Fuente: Los autores

Figura 2. Medios probatorios y las variables del pentágono del fraude

Una vez desarrollado el encargo de auditoría, el auditor podrá allegar al proceso la confesión por parte del implicado, en concordancia con el CGP, en su artículo 191, siempre y cuando esta cumpla con los requisitos legales. En este aspecto la Sentencia C-782/05 aclara que existen dos características de la confesión en un proceso penal; la primera, que no puede ser provocada mediante interrogatorio de parte sometido a la formalidad previa del juramento, y la segunda, que ha de ser corroborada por otros medios de prueba. Es de aclarar que el auditor no solo debe presentar la confesión, sino también evidencias que sustenten la validez de la confesión.

Con la inspección judicial, dentro del encargo de auditoría, se debe tener en cuenta que es una facultad excepcional del juez y previa petición de la Fiscalía o la defensa, con ciertos requisitos: i) necesidad de la práctica para establecer cómo ocurrieron los hechos e ii) imposibilidad de exhibir y autenticar en la audiencia los elementos materiales probatorios y evidencia física, o cualquier otra evidencia demostrativa. En este orden de ideas, los implicados conocen de la misma y el auditor deberá realizar pruebas sustantivas y de cumplimiento que generen la evidencia que requiera el caso. 
En los documentos, el auditor forense allegará facturas, recibos, circularizaciones, extractos bancarios, comprobantes de pago, y cualquier prueba documental que se haya generado, producto de las pruebas practicadas. Adicionalmente, en búsqueda de la verdad, el auditor podrá demostrar que un documento fue alterado, y para ello, requiere de otros expertos como de un forense de seguridad informático, para revisar si se han cambiado registros contables, el usuario que lo realizó, la fecha, el computador en el que se generó ese cambio, la huella digital por donde entró al sistema y si dejó algún tipo de virus informático o puerta de entrada para volver y seguir afectando a la organización.

El auditor puede generar del sistema de información, material probatorio como informes específicos que soportan hechos económicos no autorizados o autorizados por el implicado. Por ejemplo, informe mensual de ventas, informe de tesorería, informe de producción, informe de compras, informe de pagos; en fin, estos informes sirven de medio probatorio, pero deberán estar acompañados de los documentos fuente.

En materia probatoria al dictamen pericial le confiere una doble condición: a) como instrumento para que el juez pueda comprender aspectos fácticos del asunto, al tener carácter técnico, científico o artístico, y b) el experticio, que es un medio de prueba en sí mismo, que permite comprobar, a través de valoraciones técnicas o científicas, hechos materia de debate en un proceso (Sentencia C-124/11); en este sentido, el auditor forense, actuando como auxiliar de justicia, puede allegar al proceso su dictamen con las evidencias necesarias para que el juez pueda fallar.

Cada uno de los medios probatorios otorgan al auditor las herramientas para poder establecer qué variable del fraude es la que se presenta en caso y en este orden de ideas, muchos de los implicados al observar el trabajo del auditor, saben que serán descubiertos y prefieren confesar los hechos delictivos, para obtener rebajas por sus confesiones. Cada uno de los implicados aprovecharon los riesgos presentes en la organización y dejaron entrever a todos los stakeholders, qué tan vulnerable es la empresa.

\section{CONCLUSIONES}

El fraude ha venido evolucionando desde su perspectiva geométrica, partiendo del triángulo del fraude, en el que se contemplaban tan solo 3 variables; pero actualmente -en el pentágono del fraude- son 5 variables las que podrían suscitarlo. Esta situación hace que la articulación entre los mecanismos del Estado, de las organizaciones y de los profesionales que ejercen el encargo de 
la auditoría evolucionen en este mismo sentido, permitiendo robustecer los mecanismos de control y del levantamiento de la información en el proceso de auditoría, a fin de que la prueba levantada en el encargo tenga plena validez en un proceso judicial; sin embargo, el desconocimiento del procedimiento legal para el levantamiento de la prueba - y que esta se revista de legalidad en un proceso judicial- es una debilidad, puesto que en los casos que se detecta un fraude financiero -según cifras de KPMG en el año 2018-, el 45\% de estos fraudes no son recuperables a nivel económico, y aún más, el 33\% de estos no fueron sancionados, incluso después de haberse evidenciado el acto delictivo.

Así las cosas, el Código General del Proceso en Colombia, específicamente la Ley 1564 de 2012, tipifica los medios probatorios que se deben tener en cuenta en un proceso judicial, a fin de que se respete con ellos el debido proceso y la cadena de custodia de los mismos, para que puedan ser tenidos en cuenta en el proceso. Los medios probatorios contemplados en el CGP son: la declaración de parte, la confesión, el juramento, el testimonio, el dictamen pericial, la inspección judicial, los documentos, los indicios, los informes y otros. Estos medios permitirán al auditor o al profesional que ejerce el encargo de auditoría hacer el levantamiento de la prueba de conformidad con la normatividad vigente, y harán posible que el juez dirima los conflictos de legalidad, veracidad y oportunidad de la prueba que se allegue para ser tenida en cuenta en el proceso.

Concomitante con lo anterior, cada uno de los elementos probatorios tipificados en la ley 1564 de 2012 sirven como mecanismos para dar validez a las pruebas que se levanten en el proceso de auditoría teniendo como base la utilización adecuada de la herramienta denominada "pentágono del fraude», de conformidad con el debido proceso, la cadena de custodia y las normas internacionales de aseguramiento de la información NAI, que además de ser articuladas con los medios establecidos por el CGP coadyuvarán a la efectividad en el encargo de auditoría.

Ahora bien, teniendo en cuenta que las variables tipificadas en el pentágono del fraude arrojan un nivel alto de ocurrencia, y tal como se evidencia en los resultados de la encuesta de KPMG en el año 2018, el 53\% de los casos de delitos detectados estaban asociados a la oportunidad, y sus daños colaterales fueron observados en la moral del personal, en un $29,09 \%$ no se tiene claridad de los daños asociados al personal, lo cual, por medio de técnicas de investigación -de auditoría forense- en asocio con el buen uso de los medios probatorios consagrados en el Código General del Proceso (CGP) podría contribuir significativamente a identificar esta problemática, para que -con esta información- puedan aplicarse los controles necesarios o robustecer los ya existentes. 


\section{REFERENCIAS}

Aros, L. H. A. H., \& Cossio, L. C. G. (2015). El dictamen pericial contable, medio de prueba y criterios de valoración. Diálogos de saberes, (42), 91-102. Recuperado el 18 de mayo de 2018 de http://revistas.unilibre.edu.co/index.php/dialogos/ article/view/190/143

Asamblea Nacional Constituyente. (1991). Constitución Política de Colombia. Bogotá: Legis. http://wsp.presidencia.gov.co/Normativa/Documents/ConstitucionPolitica-Colombia.pdf

Congreso de la República de Colombia. (31 de agosto de 2004). Ley 906 de 2004. Por la cual se expide el Código de Procedimiento Penal. (Corregida de conformidad con el Decreto 2770 de 2004). Diario Oficial 45658 del 1. ${ }^{\circ}$ septiembre de 2004. Recuperado de goo.gl/ZPPkbx

. (12 de julio de 2012). Ley 1564 de 2012. Por medio de la cual se expide el Código General del Proceso y se dictan otras disposiciones. Diario Oficial 48489 del 12 julio de 2012. Recuperado de goo.gl/kXpwJd

. (14 de diciembre de 2015). Decreto 2420 de 2015. Por medio del cual se expide el Decreto Único Reglamentario de las Normas de Contabilidad, de Información Financiera y de Aseguramiento de la Información y se dictan otras disposiciones. Diario Oficial 49.726 de 14 de diciembre de 2015. Recuperado de https:/ /www.cancilleria. gov.co/sites/default/files/Normograma/docs/decreto_2420_ 2015.htm

Contribuciones a las Ciencias Sociales. (01 de junio de 2012). La presunción de inocencia y la carga de la prueba. (J. C. M. Coll, Editor) Recuperado el 15 de junio de 2018, de http://www.eumed.net/rev/cccss/20/yst3.html

Corte Constitucional, Sentencia C-067/03, MP Monroy Cabra, http:/ / www.cortecons titucional.gov.co/relatoria/2003/c-067-03.htm

Corte Constitucional, Sentencia T-916/08, MP Vargas Hernández, Clara Inés. http:/ / www.corteconstitucional.gov.co/relatoria/2008/T-916-08.htm

Corte Constitucional, Sentencia C-124/11, http:/ / www.corteconstitucional.gov.co/ RELATORIA/2011/C-124-11.htm

Cruz, J. E. (30 de octubre de 2013). Consideraciones sobre el muestreo de auditoría: selección de evidencias e impacto en los riesgos de detección. Recuperado el 15 de noviembre de 2017, de http:// publicaciones.urbe.edu/index.php/cicag/article/view/2243/4054 
Curvelo Hassán, J. O., García, M., Sandoval Sánchez, N. M., Hernández Aros, L., Flórez Guzmán, M. H., Gallego Cossio, L., . . Ladino, N. E. (2018). Visiones de la contabilidad en el siglo XXI. «manifestaciones de las prácticas de aseguramiento financiero, a partir de estudios de caso emblemáticos en colombia» (Vol. IV). (M. H. Guzmán, Ed.) Bogotá, Cundinamarca, Colombia: Ediciones Nueva Jurídica. Recuperado el 15 de junio de 2018.

Fernández Montaño, M. (2016). Nuevas tendencias en auditoría: análisis de datos y aseguramiento continuo. Fides et Ratio. Revista de difusión cultural y científica de la Universidad La Salle en Bolivia, 12(12), 193-208. Recuperado en 18 de julio de 2018, de http:/ / www.scielo.org.bo/scielo.php?script=sci_arttext\&pid=S2071081X2016000200011\&lng=es\&tlng=es.

Flórez-Guzmán, M. H., Hernández-Aros, L., \& Gallego-Cossio, L. C. (2015). Tableros de control como herramienta especializada: perspectiva desde la auditoría forense. Cuadernos de Contabilidad, 16(spe42), 661-687.

Galvis-Castañeda, I., \& Santos-Mera, J. (2017). Geometría del fraude. Cuadernos de Contabilidad, 18(45). https:/ / doi.org/10.11144/Javeriana.cc18-45.geof

KPMG. (30 de agosto de 2018). Falta de controles internos y debilidad en la cultura ética, principales causas de fraude en las empresas. Recuperado el 30 de agosto de 2018, de La corrupción y el fraude no son un mal que ataca únicamente al sector público: https://home.kpmg.com/co/es/home/media/Notas\%20de\%20prensa/ 2018/08/fraude-en-las-empresas.html

Orta Pérez, M., Castillo Lara, L., Sánchez-Mejía H., \& Sierra Molina G. J. (2012). Fundamentos teóricos de Auditoría Financiera (págs. 15-19). Madrid: Piramide.

Presidencia de la República de Colombia. (6 de agosto de 1970). Decreto 1400 de 1970. Por el cual se expide el Código de Procedimiento Civil. Diario Oficial 33150 del 21 de septiembre de 1970. Recuperado de goo.gl/bTC9pi

Quijano Parra, Jairo (s. f.). Algunos apuntes de la prueba indiciaria. Recuperado el 15 de noviembre de 2017, de http://www.sic.gov.co/sites/default/files/files/ Apuntes\%20de\%20la\%20prueba\%20indiciaria.pdf

Ruiz Jaramillo, L. B. (2009). Valoración de la validez y de la eficacia de la prueba. Aspectos epistemológicos y filosófico-políticos.

Sala Plena de la Corte Constitucional. Sentencia C-782-05 (2005). http:// www.corteconstitucional.gov.co/relatoria/2005/C-782-05.htm 